www.jmscr.igmpublication.org

Impact Factor (SJIF): 6.379

Index Copernicus Value: 71.58

ISSN (e)-2347-176x ISSN (p) 2455-0450

crossrefDOI: https://dx.doi.org/10.18535/jmscr/v6i7.200

Journal Of Medical Science And Clinical Research

\title{
The impact of training in medical education technology as perceived by the teaching faculty in their own teaching practices
}

\author{
Authors \\ Jacob K Jacob ${ }^{1}$, R. Sajith Kumar ${ }^{2}$, Manjula $V^{3}$ \\ ${ }^{1}$ Professor, Department of Medicine, GMC Ernakulam \\ ${ }^{2}$ Professor and Chief, Infectious Diseases and Medical Education, GMC, Kottayam \\ ${ }^{3}$ Professor and HOD, Community Medicine, GMC Ernakulam
}

\begin{abstract}
There is an increasing need for improving faculty development for ensuring quality in medical education in India with a fast growing number of medical colleges. There are very few studies which highlight the selfperception of the faculty regarding the impact of such training in medical education technology on their own teaching practice. Although the impact can be evaluated by various means, a self-evaluation of one's own perception of the impact is an emerging concept.

Objective: To study the impact of training in medical education technology on one's own teaching practice as perceived by the teaching faculty themselves.

Type of stud /Study design: Cross-sectional, Descriptive, Quantitative study.

Study setting: Government Medical College, Ernakulam.

Period of study: 3 months November $15^{\text {th }} 2017$ to February 15 $15^{\text {th }}$ 2018. Data collection and analysis: The confidential peer-validated questionnaire ${ }^{15}$ was the study tool used for collecting the data and data analysis was done using SPSS 16 software.

Results: $69.8 \%$ perceived a change in their teaching practice and all of them attributed this change to the formal Training in Medical education Technology (TIMET) which they have received. The overall rating of teaching practice before and after the training was compared by applying paired test and the difference was found to be statistically significant with a P value of 0.001 .

Conclusion: The majority perceived a statistically significant change in their teaching practice over the years and all of them attributed this change to the formal training in medical education technology (TIMET) which they have received.

Recommendation: The recommendation from this study is that a basic training in medical education technology has to be included very early in the career of a medical professional which can be escalated in content and practice during residency and later on continued during the formal teaching practice as a faculty.
\end{abstract}

\section{Introduction}

In most countries, educators of health professionals are poorly prepared as teachers and trainers but their clinical knowledge and skills may be good. There is an increasing need for improving faculty development for ensuring quality in medical education in India with a fast growing number of medical colleges. Sanjay et $\mathrm{al}^{1}$ 
reported the need for strengthening faculty development as a vehicle for ensuring quality in medical education. They highlighted that success of educational reforms ultimately lies with the individual instructors and their capacity, individually and collectively to execute and implement some novel ways in teaching and training the future cadre of doctors and more importantly with India thus progressively becoming a new global hub of education.

Whatever be the educational reforms we plan the success lies with each instructor and their capacity, individually and collectively to execute and implement the new ways in teaching and training the future cadre of doctors. So faculty development efforts should train the medical teachers so that their passion in teaching will progress and they will be lifelong learners too. However the training and the transformation the teachers experience are rarely evaluated well in terms of the impact it makes. There are a few studies where the impact or effectiveness is evaluated by the students or residents. But such studies where the medical teachers themselves analyse their teaching practices in the light of the presence or absence of training in medical education technology (TIMET) are rare especially from India and hence this study is very significant. Self-evaluation is crucial in the practice of medicine, yet few educators have formally introduced self-assessment into the undergraduate medical curriculum. Results suggest that selfevaluation has educational merit as a measure of non-cognitive abilities associated with clinical performance and as a stimulus to further learning and professional development. ${ }^{2}$

Although expected of all health professionals, self-assessment skills are seldom addressed directly in training ${ }^{3}$. A previous review by Gordon M.J. ${ }^{3}$ identified curricular criteria associated with improved accuracy and validity in selfassessments of knowledge and performance in curriculum studies published between January 1970 and February 1990. Most described initial disorientation or opposition on the part of learners, attributed to unfamiliar roles and to learners' distrust. $^{3}$ The curricula that successfully negotiated the transition to self-assessment norms reported non-cognitive benefits such as improvements in morale, motivation, and communications among learners and faculty. ${ }^{3}$

Reported cognitive benefits included improvements in knowledge, performance, and self-analysis of performance. The constellation of effects suggests that effective self-assessment programs may promote more mature, collegial, and productive learning environments, particularly suited to the training of health professionals. ${ }^{3}$

Hence this study aims to look at the impact on the practice of teaching as perceived by the faculty themselves following the training in medical education technology (TIMET) they have received at some point of their career. The study is based on the hypothesis that formal training in medical education technology is very much essential and it can transform one's own practice of teaching significantly. Although the impact can be evaluated by various means, a self-evaluation of one's own perception of the impact is an emerging concept. The ability to self-assess is both crucial to clinical competence and necessary for the development of competent health care professionals.

Gap: There have been no definite efforts to analyse and not many publications on the selfperception of the teaching faculty, of the impact of training in medical education technology in their teaching practice over the years.

\section{Research question}

What is the impact of Training in Medical Education Technology (TIMET) on one's own teaching practice as perceived by the teaching faculty themselves?

Expected result / Hypothesis: Those who have undergone Training in Medical Education Technology (TIMET) have experienced a definite transformation in their teaching practice.

\section{Objectives}

To study the impact of training in medical education technology on one's own teaching 
practice as perceived by the teaching faculty themselves.

\section{Review of Literature}

A physician's ability to recognize personal strengths and weaknesses is important to their professional development in both clinical and teaching roles. This is particularly relevant after formal training has ended. ${ }^{4}$ Accurate selfassessment is central to a physician's professional growth, ${ }^{5,6}$ and may correlate with global selfesteem. ${ }^{7,8}$ Yet the accuracy of self-assessment in medicine has been variable when compared to more objective measures. ${ }^{9}$

In an almost similar study by Dona et $\mathrm{al}^{10}$ teachers' self-assessments were compared with that of learner's assessments. They surveyed their learners to compare teacher and learner assessments of teaching proficiency, behaviours, enjoyment, and career satisfaction. In each area, learners' ratings were statistically significantly higher than their teachers' self-ratings. Though it is unclear whether teachers' or learners' assessments are a more accurate reflection of the truth, the more positive learner ratings should promote self-confidence in clinician-educators regarding their teaching abilities.

Evaluation of educational program effectiveness is usually by determining that institutions and programs document the achievement of their students and graduates in verifiable and consistent ways, indicating that institutional and program purposes are met. For the assessment of medical education programs this represents a departure from the traditional method of inferring quality from institutional compliance with standards for program organization and function. In the new assessment calculus, success is measured as the integrated product of the outcomes, the indicators of achievement that medical schools already are collecting from many sources, for instance, data on premedical achievement and attributes, medical school performance, graduate education ratings and test results, specialty certification, licensure, and practice. Although a recent LCME enquiry showed that $80 \%$ of U.S. medical schools were collecting outcome data on students and graduates, there was a lack of coherence and system, little integrated analysis, rare longitudinal study, and limited use of the information to evaluate and revise the curriculum or to validate admissions, promotion, and graduation criteria. The longitudinal study of the quantified results of educational programs need not resurrect old controversies about the linkage between learning in medical school and the quality of doctors' later practice. $^{11}$

Blumberg P. In his research article outlines specific ways to consider three types of efficacy outcomes that are consistent with accreditation guidelines: educational, clinical career, and environmental outcomes. Specific measurable outcomes for each of these categories are derived from higher education literature: for example, learning approaches and information acquisition for education; professional behaviours and interpersonal dimensions for clinical career, and scholarship of teaching and teaching itself as a shared and valued activity for environmental outcomes. These outcomes address student assessment and program evaluation. Educators can determine if educational program innovations have met their goals by collecting efficacy outcome data. $^{12}$

Distance learning courses focusing on educational leadership and pedagogy for medical teachers can be an option to reach a wider audience. FDPs can be an asset in recruiting and retaining teachers as they offer valued professional development opportunities. ${ }^{1}$

As specified by the Medical Council of India (MCI), Faculty Development Programs aim to improve the quality of medical education by training and sensitizing teachers about new concepts in teaching and assessment methods; develop knowledge and clinical skills required for performing the role of competent and effective teachers, administrators, researchers and mentors; assist clinicians to acquire competency in communication and behavioural skills and update 
knowledge using modern information and research methodology tools. ${ }^{1}$

Gordon et al mentions that understanding how clinician-teachers' self-assessments compare to learners' impressions can serve to help educators place each of these evaluations in the appropriate context. Past participants of the Johns Hopkins Faculty Development Program and other physician-teachers were surveyed in 2002 regarding their teaching skills and behaviours.

They surveyed their learners to compare teacher and learner assessments of teaching proficiency, behaviours, enjoyment, and career satisfaction. In each area, learners' ratings were statistically significantly higher than their teachers' selfratings. Though it is unclear whether teachers' or learners' assessments are a more accurate reflection of the truth, the more positive learner ratings should promote self-confidence in clinician-educators regarding their teaching abilities. $^{3}$

Hewson et al investigated the usefulness of retrospective self-assessments by program participants in combination with independent ratings of teaching performance by their trainees. The retrospective self-assessments showed improvements in teaching skills that previously were identified as needs, as well as those in which participants originally felt quite competent. This evaluation strategy showed that the faculty development program improved the teaching competencies of the participants. Both the program participants' retrospective selfassessments and the independent ratings by their trainees showed post-program improvements and were positively inter-correlated. The use of such multiple measures is a viable approach to evaluate the impact of a faculty development program. Potentially either approach could be used, but in combination, they provide a feasible, valid, and reliable evaluation. ${ }^{13}$

Baldwin et al states that though it is unclear whether teachers' or learners' assessments are a more accurate reflection of the truth, combined results should give clinician-educators greater insight into how self-assessment of their teaching skills compares with their learners' assessments. The results have the potential to improve the selfesteem of clinician educators and their confidence in their teaching abilities. ${ }^{14}$

Instruments that rate teaching effectiveness provide both positive and negative feedback to clinician-educators, helping them improve their teaching. The Cleveland Clinic's Clinical Teaching Effectiveness Instrument is reliable and valid, as well as usable. It can be used as an evaluation tool for a wide variety of clinical teaching settings. ${ }^{15}$

\section{Materials and Methods}

Type of study / Study Design: Cross-sectional, Descriptive, Quantitative study

Study Setting: Government Medical College, Ernakulam

Period of study: 3 months November $15^{\text {th }} 2017$ to February $15^{\text {th }} 2018$

Sample Population and Size: The teaching faculty of GMCE who have undergone Training in Medical Education (TIMET) at some point of their career.

Sampling Method: Universal sampling

Inclusion Criteria: Faculty of GMCE who have received any training in medical education technology of more than 3 days duration at some point of their career.

\section{Exclusion Criteria}

1. Those faculty without at least a 3 day faculty training at some point of their career.

2. Faculty who are not willing to be part of the study.

Data Collection and Analysis: The confidential peer-validated questionnaire ${ }^{15}$ was the study tool used for collecting the data. The faculty who gave informed consent were given the questionnaire through another staff so that their identity was protected. It was not mandatory for them to participate in the study. To maintain the anonymity of the faculty further, names or any identity proofs were not entered in the 
questionnaire. The responses to the perception of teaching practices were assessed using 5-point Likert scale. 5 - Strongly Agree, 4 - Agree, 3 Neither Disagree nor agree, 2 - Disagree \& 1 Strongly Disagree.

Data Analysis: The data obtained from the questionnaire was first entered in a proforma, coded, grouped and entered in Microsoft Excel spread sheet and then analysed using SPSS 16. The total score obtained from the Likert scale was calculated. $>60 \%$ or more was considered good perception, $40-59 \%$ was average and $<40 \%$ poor. The overall perception of teaching experience before and after the TIMET plotted by the faculty on a on 0 to 10 scale was compared using the paired t test.

\section{Results}

The data was entered and analysed as mentioned in the methodology and the following results were obtained.

Table 1 Showing the cross-tabulation of age and gender

\begin{tabular}{|c|c|c|c|c|c|}
\hline \multicolumn{6}{|c|}{ Age-Gender } \\
\hline & & & \multicolumn{2}{|c|}{ Gender } & \multirow[t]{2}{*}{ Total } \\
\hline & & & Male & Female & \\
\hline \multirow[t]{6}{*}{ Age gp } & \multirow[t]{2}{*}{$30-40$} & Count & 5 & 11 & 16 \\
\hline & & $\%$ within agegp & $31.2 \%$ & $68.8 \%$ & $100.0 \%$ \\
\hline & \multirow[t]{2}{*}{$41-50$} & Count & 11 & 15 & 26 \\
\hline & & $\%$ within agegp & $42.3 \%$ & $57.7 \%$ & $100.0 \%$ \\
\hline & \multirow[t]{2}{*}{$>50$} & Count & 5 & 6 & 11 \\
\hline & & $\%$ within agegp & $45.5 \%$ & $54.5 \%$ & $100.0 \%$ \\
\hline \multirow{2}{*}{\multicolumn{2}{|c|}{ Total }} & Count & 21 & 32 & 53 \\
\hline & & $\%$ within agegp & $39.6 \%$ & $60.4 \%$ & $100.0 \%$ \\
\hline
\end{tabular}

Females outnumbered males in each age group in the study population.

Table 2 Showing the descriptive statistics

\begin{tabular}{|l|c|c|c|c|c|}
\hline \multicolumn{7}{|l|}{ Descriptive Statistics } & $\mathrm{N}$ & Minimum & Maximum & Mean & Std. Deviation \\
\hline Age & 53 & 30 & 65 & 45.42 & 7.373 \\
\hline T.Exp. (Years) & 53 & 4 & 25 & 12.96 & 4.946 \\
\hline TIMET (Yrs before) & 53 & 1 & 18 & 4.38 & 4.235 \\
\hline Valid N (list wise) & 53 & & & & \\
\hline
\end{tabular}

The minimum age was 30 years and the peak age was 65 years. Years of teaching experience varied from 4 years to 25 years. Training was undertaken 1 year before the study to 18 years before.

Table 3 - Table showing stream - cadre cross tabulation

\begin{tabular}{|c|c|c|c|c|c|c|}
\hline \multicolumn{7}{|c|}{ Stream * Cadre Cross tabulation } \\
\hline & & & \multicolumn{3}{|c|}{ Cadre } & \multirow[t]{2}{*}{ Total } \\
\hline & & & $\begin{array}{l}\text { Assistant } \\
\text { Professor }\end{array}$ & $\begin{array}{l}\text { Associate } \\
\text { Professor }\end{array}$ & Professor & \\
\hline \multirow[t]{6}{*}{ Stream } & \multirow[t]{2}{*}{ Pre clinical } & Count & 9 & 2 & 0 & 11 \\
\hline & & $\%$ within Stream & $81.8 \%$ & $18.2 \%$ & $.0 \%$ & $100.0 \%$ \\
\hline & \multirow[t]{2}{*}{ Para clinical } & Count & 6 & 4 & 3 & 13 \\
\hline & & $\%$ within Stream & $46.2 \%$ & $30.8 \%$ & $23.1 \%$ & $100.0 \%$ \\
\hline & \multirow[t]{2}{*}{ Clinical } & Count & 16 & 8 & 5 & 29 \\
\hline & & $\%$ within Stream & $55.2 \%$ & $27.6 \%$ & $17.2 \%$ & $100.0 \%$ \\
\hline \multirow{2}{*}{\multicolumn{2}{|c|}{ Total }} & Count & 31 & 14 & 8 & 53 \\
\hline & & $\%$ within Stream & $58.5 \%$ & $26.4 \%$ & $15.1 \%$ & $100.0 \%$ \\
\hline
\end{tabular}

The cadres and stream almost corresponded to the MCI norms. 
Table 4 Showing the details of previous such evaluation of their teaching practice.

\begin{tabular}{|c|c|c|c|c|c|}
\hline \multicolumn{6}{|c|}{ Stream * Previous evaluation Cross-tabulation } \\
\hline & & & \multicolumn{2}{|c|}{ Previous evaluation } & \multirow[t]{2}{*}{ Total } \\
\hline & & & Yes & No & \\
\hline \multirow[t]{6}{*}{ Stream } & \multirow[t]{2}{*}{ Preclinical } & Count & 4 & 7 & 11 \\
\hline & & $\%$ within Stream & $36.4 \%$ & $63.6 \%$ & $100.0 \%$ \\
\hline & \multirow[t]{2}{*}{ Para clinical } & Count & 3 & 10 & 13 \\
\hline & & $\%$ within Stream & $23.1 \%$ & $76.9 \%$ & $100.0 \%$ \\
\hline & \multirow[t]{2}{*}{ Clinical } & Count & 5 & 24 & 29 \\
\hline & & $\%$ within Stream & $17.2 \%$ & $82.8 \%$ & $100.0 \%$ \\
\hline \multirow{2}{*}{\multicolumn{2}{|c|}{ Total }} & Count & 12 & 41 & 53 \\
\hline & & $\%$ within Stream & $22.6 \%$ & $77.4 \%$ & $100.0 \%$ \\
\hline
\end{tabular}

Only $22.6 \%$ of the faculty has filled up such a such an evaluation questionnaire or had any kind questionnaire before and $77.4 \%$ have not filled up of evaluation any time in their teaching practice.

Table 5 Showing the perception of the faculty regarding the change they have noticed in their teaching practice.

\begin{tabular}{|l|c|c|c|c|}
\hline Domain & Agree & Neutral & Disagree & Total \\
\hline Perception of change in teaching practice & $37(69.8)$ & $11(20.8)$ & $5(11.4)$ & $53(100)$ \\
\hline Change in TP is due to MET training & $37(69.8)$ & $12(22.6)$ & $4(7.5)$ & $53(100)$ \\
\hline
\end{tabular}

$69.8 \%$ perceived a change in their teaching practice and all of them attributed this change to the formal Training in Medical education
Technology which they have received. But this was not statistically significant probably due to the small sample which was studied.

Table 6 Showing the details of teacher - student relationship as the faculty perceived.

\begin{tabular}{|l|c|c|c|c|}
\hline Self assessment based on student factors & Agree & Neutral & Disagree & Total \\
\hline $\begin{array}{l}\text { Student's performance, interest, } \\
\text { attendance and knowledge }\end{array}$ & $24(45.3)$ & $21(39.6)$ & $8(15.1)$ & $53(100)$ \\
\hline Teacher student relationship & $37(67.9)$ & $13(24.5)$ & $4(7.5)$ & $53(100)$ \\
\hline Better learning environment & $36(67.9)$ & $15(28.3)$ & $2(3.8)$ & $53(100)$ \\
\hline Encourage to ask doubts & $47(88.7)$ & $6(11.3)$ & $0(0)$ & $53(1000$ \\
\hline Offer and give feedback & $32(60.4)$ & $15(28.3)$ & $6(11.3)$ & $53(100)$ \\
\hline Students recognise change in TP & $17(32.1)$ & $27(50.9)$ & $9(17)$ & $53(100)$ \\
\hline
\end{tabular}

$45 \%$ noticed a change in student behaviour due to the change in their teaching practise. $67.9 \%$ felt that the teacher-student relationship improved. $67.9 \%$ felt that the learning environment has improved. $88.7 \%$ felt that they encourage more doubts from students. $60.4 \%$ offered and gave feedback. Only $32 \%$ felt that the students recognised this change in the faculty's teaching practices.

Table 7 Showing the levels where the faculty experienced transformation

\begin{tabular}{|l|c|c|c|c|}
\hline Change in Teaching practice & Agree & Neutral & Disagree & Total \\
\hline Transformation in affective domain & $42(79.2)$ & $9(17.0)$ & $2(3.8)$ & $53(100)$ \\
\hline Demonstrate clinical skills & $41(77.4)$ & $11(20.8)$ & $191.9)$ & $53(100)$ \\
\hline Concern for students & $37(69.8)$ & $13(24.5)$ & $3(5.7)$ & $53(100)$ \\
\hline Communication skills & $35(66.0)$ & $15(28.3)$ & $3(5.7)$ & $53(100)$ \\
\hline Use more teaching aids & $30(52.8)$ & $16(30.2)$ & $9(17.0)$ & $53(100)$ \\
\hline Better time management & $28(52.8)$ & $16(30.2)$ & $9(17.0)$ & $53(100)$ \\
\hline Traditional to newer TL methods & $37(69.8)$ & $11(20.8)$ & $5(9.4)$ & $53(100)$ \\
\hline Developed interest in research & $32(60.4)$ & $16(30.2)$ & $5(9.4)$ & $53(100)$ \\
\hline More on project based learning & $30(56.6)$ & $12(22.6)$ & $11(20.8)$ & $53(100)$ \\
\hline Teaching is JOY & $42(79.2)$ & $10(18.9)$ & $1(1.9)$ & $53(100)$ \\
\hline
\end{tabular}

$79.2 \%$ experienced this change in affective domain. $77.4 \%$ experienced change in demonstrating skills more, $69.8 \%$ experienced a more concern for students, $66 \%$ experienced 
improvement in communication skills, $52.8 \%$ started using more teaching aids and better time management, $60.4 \%$ developed more interest in research and 56.6\% used more project based teaching and $56.6 \%$ felt teaching is a JOY now.

Table 8 Showing the comparison of the rating of teaching practice before and after the TIMET.

\begin{tabular}{|l|c|c|c|}
\hline Comparison of rating of teaching practice (N=53) & Mean & Standard deviation & P value \\
\hline Before training & 5.91 & 1.42 & 0.001 \\
\hline After training & 7.23 & 1.42 & \\
\hline
\end{tabular}

The overall rating of teaching practice was compared by applying paired t test . The mean of the overall self-rating of teaching before TIMET was 5.91 and after TIMET was 7.23 and the difference was found to be statistically significant with a $\mathrm{P}$ value of 0.001 . This indicates that even though the population under study was relatively small and a covered a wide range of faculty in terms of age, sex, experience of teaching and previous TIMET there is a uniform and significant perception among the faculty that a structured and timely Training in Medical Education Technology can alter their practice of teaching so that the students and in turn the community at large will benefit.

Table 9 Showing the perception of training variables among the faculty population under study.

\begin{tabular}{|l|c|c|c|c|}
\hline Training variables & Agree & Neutral & Disagree & Total \\
\hline Desire to undergo further training & $40(75.5)$ & $9(17.8)$ & $4(7.5)$ & $53(100)$ \\
\hline So old to undergo training & $2(3.8)$ & $79(13.2)$ & $44(83.0)$ & $53(100)$ \\
\hline Busy to undergo training & $7(13.2)$ & $119(20.8)$ & $35(66.0)$ & $53(100)$ \\
\hline Not necessary to go further training & $2(3.8)$ & $11(20.8)$ & $40(75.50)$ & $53(100)$ \\
\hline Recommend training at start of carrier & $48(90.6)$ & $2(3.8)$ & $3(5.7)$ & $53(100)$ \\
\hline
\end{tabular}

$75 \%$ expressed their desire to undergo further training. $20 \%$ were unwilling for further training due to age, busy schedule etc. $90.6 \%$ felt that such training in medical education technology is needed at the start of the carrier itself.

\section{Discussion}

Piaget $^{16}$ noted that the success of educational reforms ultimately lies with individual instructors and their capacity, individually and collectively, to implement "new ways of doing things" during their day-to-day, hour-by-hour, moment-bymoment interactions with students.

In our study only $22.6 \%$ of the faculty has filled up such a questionnaire before and $77.4 \%$ have not filled up such an evaluation questionnaire or had any kind of evaluation any time in their teaching practice. This indicates the lack of adequate self evaluation practices. $69.8 \%$ perceived a change in their teaching practice and all of them attributed this change to the formal Training in Medical education Technology (TIMET) which they have received. But this was

not statistically significant probably due to the small sample which was studied.

$45 \%$ noticed a change in student behaviour due to the change in their teaching practise. $67.9 \%$ felt that the teacher-student relationship improved. $67.9 \%$ felt that the learning environment has improved. Only $32 \%$ felt that the students recognised this change in the faculty's teaching practices.

The overall rating of teaching practice was compared and the difference was found to be statistically significant. This indicates that even though the population under study was relatively small and covered a wide range of faculty in terms of age, sex, experience of teaching and previous TIMET, there is a uniform and significant perception among the faculty that a structured and timely Training in Medical Education Technology can alter their practice of teaching so that the students and in turn the community at large will benefit. 
A large proportion (75\%) expressed their desire to undergo further training. This again is a good perception. The rest were unwilling for further training due to age, busy schedule, lack of adequate basic exposure etc. Almost everyone $(90.6 \%)$ felt that such training in medical education technology is needed at the start of the carrier itself.

The overall rating of teaching practice was compared and found statistically significant indicating that even though the population under study was relatively small and a covered a wide range of faculty in terms of age, sex, experience of teaching and duration after the previous TIMET, there was a uniform and significant perception among the faculty that a structured and timely Training in Medical Education Technology can alter their practice of teaching so that the students and in turn the community at large will benefit. Almost everyone felt that such training in medical education technology is needed at the start of the carrier itself.

Steinhert et $\mathrm{al}^{17}$ concluded in their study that faculty development activities appear highly valued by participants, who also report changes in learning and behaviour. Notwithstanding the methodological limitations in the literature, certain program characteristics appear to be consistently associated with effectiveness.

In the present study $75 \%$ expressed their desire to undergo further training. $90.6 \%$ felt that such training in medical education technology is needed at the start of the carrier itself. This may be irrespective of taking up teaching carrier because a doctor in the community is always a leader, teacher and trainer.

Joshi et al ${ }^{18}$ studied the outcome of the impact of teacher training workshops on faculty teaching performance where all the respondents found the teacher training to be very useful for improvement of teaching skills. In their study a total of $76.66 \%$ said that the skills learnt in the workshop were very applicable, $80 \%$ perceived changes in students' classroom behaviour and found their lecture to be more participatory and interactive and as for their own change in behaviour, $66.66 \%$ respondents experienced better interaction with the students in classroom and the overall impression of the training was very positive. The results are comparable with that of the present study.

Van Der Leeuw RM et $\mathrm{al}^{19}$ investigated how aspects of a teaching performance evaluation system may affect faculty's teaching performance improvement as perceived by residents over time. The average response rate over three years was $69 \%$ for faculty and $81 \%$ for residents. They concluded that evaluation systems on clinical teaching performance appear helpful in enhancing teaching performance in residency training programs.

Mythili et $\mathrm{al}^{20}$ studied the perceptions of medical teachers on the faculty development programme and found in their study that the feedback in the Liker scale format from more than $95 \%$ of the participants pronounced the usefulness of the programme and the statistically significant post test marks and the Feedback (Likertscale) from the participants highlighted the necessity of the training.

Accurate self-assessment is central to a physician's professional growth, ${ }^{5,6}$ and may correlate with global self-esteem. ${ }^{7,8}$ Yet the accuracy of self-assessment in medicine has been variable when compared to more objective measures. ${ }^{9}$

\section{Conclusion and Recommendation}

The majority perceived a statistically significant change in their teaching practice over the years and all of them attributed this change to the formal training in medical education technology (TIMET) which they have received. Thus there was a uniform perception among the faculty that a structured and timely Training in Medical Education Technology can alter their practice of teaching so that the students and in turn the community at large will benefit. Such training will be of much benefit if received at the very beginning of the career itself. 
Self-assessments are useful in improving the teaching and learning programmes and attitudes. So periodic systematic self-evaluations are to be done.

The recommendation from this study is that a basic training in medical education technology has to be included very early in the career of a medical professional which can be escalated in content and practice during residency and later on continued during the formal teaching practice as a faculty. This should be irrespective of taking up teaching carrier because a doctor in the community is a life time leader, teacher and trainer wherever he will be placed.

\section{Limitations of the study}

The number of faculty who could be included in the study as per the criteria was small. Only 53 of the faculty could be included in the study which of course is a very small sample. A qualitative study also could have been done but due to the time constraints and deficiencies in the working staff pattern it was found to be not feasible during this study period.

Personnel responsible for data collection: Mrs. Sulabha, office assistant, GMC Ernakulam

Personnel responsible for data analysis: Prof. Dr. Manjula V.D., GMC Ernakulam

Ethical Considerations: The protocol was developed, peer-reviewed and presented to the IRC for suggestions and approval. The questionnaire was peer validated. It was then presented to IRB for final approval and the data collection was done during November $15^{\text {th }} 2017$ and January $15^{\text {th }} 2018$ after obtaining the IRB approval.

\section{Funding agency - Nil}

\section{References}

1. Sanjay Zodpey, Anjali Sharma, Quazi Syed Zahiruddin, Abhay Gaidhane, Sunanda Shrikhande et al. Faculty development programs for medical teachers in India. J Adv Med Edu Prof. 2016 Apr; 4(2): 97-101.

2. Arnold L, Willoughby TL, Calkins EV. Self-evaluation in undergraduate medical education: a longitudinal perspective. J Med Educ. 1985 Jan;60(1):21-8.

3. Gordon MJ. Self-assessment programs and their implications for health professions training. Acad Med.1992;67:672-9. Available from: https://www.ncbi.nlm.nih.gov/pmc/articles /PMC1492334/

4. Wooliscroft JO, TenHaken J, Smith J, Calhoun JG. Medical students' clinical self-assessments: comparisons with external measures of performance and the students' self-assessments of overall performance and effort. Acad Med. 1993;68:285-9

5. Arnold L, Willoughby TL, Calkins EV. Self-evaluation in undergraduate medical education: a longitudinal perspective. J Med Educ.1985;60:21-8.

6. Zabarenko RN, Zabarenko LM. Teaching psychological medicine on hospital rounds: a liaison experiment. Int $\mathbf{J}$ Psychiatry Med.1978;8:325-34.

7. Carmel S. The professional self-esteem of physicians scale, structure, properties, and the relationship to work outcomes and life satisfaction. Psychol Rep.1997;80:591602.

8. Rosenberg M, Schooler C, Schoenbach C, Rosenberg F. Global self-esteem and specific self-esteem: different concepts, different outcomes. Am Social Rev.1995; 60:141-56.

9. Gordon MJ. Self-assessment programs and their implications for health professions training. Acad Med.1992;67:672-9.

10. Donna M W, Amy M Knight, Scott M W. Clinician-teachers Self-assessments Versus Learners' Perceptions. J Gen Inter Med. 2004 May;19(5 Pt 2):554-557. 
11. Kassebaum DG. The measurement of outcomes in the assessment of educational program effectiveness. AcadMed.1997 Dec;72(12):1127-33;1990 May;65(5):2936. Available from: https://www.ncbi.nlm.nih.gov/pubmed/233 7430

12. Blumberg P. Multidimensional outcome considerations in assessing the efficacy of medical educational programs. Teach Learn Med. 2003 Summer;15(3):210-4. Available from: https://www.ncbi.nlm.nih.gov/pubmed/128 55393

13. Hewson MG, Copeland HL. What's the use of faculty development? Program evaluation using retrospective selfassessments and independent performance ratings. Teach Learn Med. 2001;13:15360. Available from https://www.ncbi.nlm.nih.gov/pubmed/114 75658

14. Baldwin CD, Levine HG, McCormick DP. Meeting the faculty development needs of generalist physicians in academia. Acad Med.1991;155:962-7. Available from :https://www.ncbi.nlm.nih.gov/pmc/article s/PMC1492334/

15. Copeland L.H. and Hewson M.G. The Cleveland Clinic's Clinical Teaching Effectiveness Instrument. Academic Medicine 2000;75:161-166. https://www.ncbi.nlm.nih.gov/pubmed/106 93849

16. Piaget J. New York: Orion Press; 1970. Science of education and the psychology of the child.

17. Steinert Y, Mann K, Centeno A, Dolmans D, Spencer J, Gelula M, Prideaux D. A systematic review of faculty development initiatives designed to improve teaching effectiveness in medical education: BEME Guide Med Teach. 2006 Sep;28(6):497526
18. Joshi S, Pradhan A, Dixit H Faculty opinion survey following attendance to teacher training workshops in Kathmandu Medical College. Kathmandu University Medical Journal (2003) Vol. 2, No. 3, Issue 7, 244-251

19. Van Der Leeuw RM, Boerebach BC, Lombarts KM, Heineman MJ, Arah OA. Clinical teaching performance improvement of faculty in residency training: A prospective cohort study.Med Teach. 2016 May;38(5):464-70.

20. Mythili S.V., Arul Amutha Elizabeth. Perceptions of Medical Teachers on the Faculty Development Programme. Indian J Physiol Pharmacol 2016; 60(1) : 96-101. 